\title{
UMA ANÁLISE SOBRE O ORIGINALISMO NO CONTEXTO DO ATIVISMO JUDICIAL BRASILEIRO
}

\author{
Elden Borges Souza \\ Professor no Centro Universitário Fibra (Belém/PA) e na Faculdade Ideal Wyden (Belém/ \\ PA). Doutorando e Mestre em Direito pela Universidade Federal do Pará (Belém/PA). \\ Pesquisador no Grupo de Pesquisa "Tradição da Lei Natural".
}

\section{Victor Sales Pinheiro}

Professor Adjunto da Universidade Federal do Pará (Belém/PA), da qual é membro permanente do Programa de Pós-Graduação em Direito. Coordenador do Grupo de Pesquisa "Tradição da Lei Natural". Doutor em Filosofia pela Universidade do Estado do Rio de Janeiro. Mestre em Filosofia pela Pontifícia Universidade Católica do Rio de Janeiro.

\begin{abstract}
Resumo: O Brasil possui um sistema de controle de constitucionalidade relativamente consolidado, sendo prova disto o lugar de destaque dado ao Supremo Tribunal Federal em casos jurídicos controversos. Como consequência, tornou-se um lugar comum afirmar que o Tribunal adota uma postura ativista no exercício da jurisdição constitucional. No entanto, por um lado, não é possível identificar claramente uma teoria que fundamente e justifique esse modo de atuação. Por outro lado, são ignoradas no debate constitucional nacional as teorias que contestam, de alguma forma, essa forma de manifestação do controle de constitucionalidade. Nesse sentido, um debate importante no âmbito anglo-saxão é entre o originalismo e o não originalismo na interpretação constitucional. Assim, o objetivo deste trabalho é, recepcionando no Brasil esse debate já existente na América do Norte, analisar o originalismo interpretativo no contexto do ativismo judicial existente no Supremo Tribunal Federal, apresentando uma análise crítica de ambos. Para tanto, o trabalho faz uma análise do contexto constitucional brasileiro; apresenta uma estrutura para a compreensão dos tipos de ativismo judicial; discute as diferenças entre originalismo e não originalismo; e, por fim, analisa a possibilidade de inserção do originalismo no modelo constitucional brasileiro. A pesquisa foi desenvolvida a partir de uma pesquisa bibliográfica, tomando como autores principais sobre o contexto brasileiro Conrado Hübner e Luís Roberto Barroso e, sobre o originalismo, Wilfrid Waluchow e Lawrence Solum.
\end{abstract}

Palavras-chave: Interpretação constitucional. Supremo Tribunal Federal. Originalismo. Ativismo judicial. Controle de constitucionalidade.

Sumário: 1 Introdução - $\mathbf{2} 0$ contexto brasileiro: constitucionalismo e ativismo judicial - $\mathbf{3}$ Sobre uma teoria do ativismo judicial $\mathbf{-} \mathbf{4}$ Constitucionalismo, originalismo e interpretação judicial - $\mathbf{5}$ Originalismo no Brasil: possibilidades e desafios - $\mathbf{6}$ Conclusão - Referências 


\section{Introdução}

Tornou-se um lugar comum no debate político e judicial brasileiro afirmar que o Supremo Tribunal Federal adota uma postura ativista no exercício da jurisdição constitucional. No entanto, ao mesmo tempo, não é possível identificar claramente uma teoria que fundamente e justifique esse modo de atuação. Na realidade, uma percepção superficial e inicial sobre esse debate leva a crer que há um déficit teórico na atuação da Suprema Corte brasileira. Portanto, faz-se necessário um repensar do conceito de ativismo judicial, dentro da jurisdição constitucional brasileira, a partir de uma teoria da interpretação constitucional mais ampla.

No debate instalado nos Estados Unidos e no Canadá, uma divisão teórica sobre a interpretação constitucional ganhou destaque, o debate sobre a viabilidade ou não de uma teoria interpretativa assentada na origem da Constituição. Embora formada por concepções teóricas mais específicas, podemos fazer uma divisão mais ampla neste debate entre o originalismo e o não originalismo. A partir dessa divisão mais geral, poderemos compreender as proposições e as críticas a uma concepção originalista de interpretação constitucional.

O objetivo deste trabalho é, recepcionando no Brasil o debate já existente na América do Norte, analisar o originalismo interpretativo no contexto do ativismo judicial atualmente existente no Supremo Tribunal Federal, apresentando uma análise crítica do ativismo judicial e do próprio originalismo. Como será visto, embora seja importante destacar desde o início, esse debate possui um plano epistemológico e um plano político, sendo o objetivo principal a discussão do plano político - isto é, sobre a atuação do Judiciário e sua relação, especialmente, com a Constituinte e o Legislativo.

O desafio, a ser destacado desde o início, é a falta de clareza na adoção de teorias da interpretação constitucional pela Suprema Corte brasileira, de forma que o presente trabalho busca identificar e interligar a realidade judicial brasileira a uma teoria de fundo que fundamente (e permita a crítica) de nossa prática judiciária.

Nesse objetivo, o presente trabalho inicia apresentando, de forma sintética, o contexto da jurisdição constitucional brasileira, especialmente no que diz respeito ao modelo baseado no ativismo judicial. Em seguida, se apresenta uma estrutura teórica para o ativismo judicial, destacando a diferença nas suas hipóteses de manifestação. Em um terceiro momento, será apresentada uma síntese das concepções constitucionais de base originalista e não originalista. Por fim, será discutida as possibilidades e desafios a um originalismo na Constituição de 1988.

A pesquisa foi desenvolvida a partir de uma pesquisa bibliográfica, de forma dedutiva e dialética, tomando como autores principais sobre o contexto brasileiro 
Conrado Hübner e Luís Roberto Barroso e, sobre o originalismo, Wilfrid Waluchow e Lawrence Solum.

\section{0 contexto brasileiro: constitucionalismo e ativismo judicial}

Antes de discutir a interpretação constitucional no Brasil, é importante compreender o papel do Judiciário nessa interpretação. Então, será possível compreender os desafios que a conjugação entre o ativismo judicial e o modelo adotado pela Constituição de 1988 pode gerar e, consequentemente, a necessidade de uma teoria interpretativa de fundo - o que inclui uma dimensão epistemológica e, especialmente, política.

Em primeiro lugar, é importante identificar o lugar do Judiciário (e do Supremo Tribunal Federal) na interpretação constitucional brasileira. Como destaca Conrado Hübner Mendes, ${ }^{1}$ embora o sistema constitucional brasileiro permita que o Legislativo altere a interpretação dada pelo Supremo Tribunal Federal (por meio de uma emenda constitucional), a última palavra permanece com o Judiciário, que ainda pode declarar a inconstitucionalidade da alteração realizada pelo Legislativo. ${ }^{2}$ Isso indica, claramente, a centralidade no Judiciário, especialmente da Suprema Corte, na interpretação final da Constituição Federal de 1988.

Aliás, destaca Mendes, essa possibilidade é completamente excepcional mesmo entre os países com um sistema de jurisdição constitucional próximo ao brasileiro. ${ }^{3} \mathrm{Na}$ verdade, o Supremo Tribunal Federal foi o primeiro tribunal do qual se tem registro a declarar a inconstitucionalidade de uma alteração da Constituição, mesmo existindo outros países com cláusulas pétreas em suas cartas constitucionais. ${ }^{4}$ Ou seja, o Tribunal se afirma, de forma incontestável, como o detentor da última palavra em matéria de interpretação da Constituição. Aliás, poder-se-ia afirmar que é a Constituição que atribui essa prerrogativa ao Tribunal. No entanto, como será visto ao longo deste trabalho, esta prerrogativa parece ser decorrente muito mais da postura da Corte do que consequência de alguma previsão constitucional específica.

1 MENDES, Conrado Hübner. Controle de constitucionalidade e democracia. Rio de Janeiro: Elsevier, 2008. p. 134.

2 Considerando que os leitores deste trabalho conheçam o sistema de controle de constitucionalidade brasileiro, não se pretende avançar muito com a exposição sobre as formas e regras pátrias para a intervenção do Judiciário na análise da constitucionalidade das normas jurídicas.

3 MENDES, Conrado Hübner. Controle de constitucionalidade e democracia. Rio de Janeiro: Elsevier, 2008. p. 146.

4 MENDES, Conrado Hübner. Controle de constitucionalidade e democracia. Rio de Janeiro: Elsevier, 2008. p. 146. 
Outro aspecto relevante sobre o contexto brasileiro é a ampliação da jurisdição constitucional nas últimas duas décadas. Após a promulgação da Constituição brasileira de 1988, especialmente em razão da influência do denominado neoconstitucionalismo (ou novo constitucionalismo) sobre a doutrina nacional, foi desenvolvida uma jurisprudência em que a atuação do Judiciário é central para a solução dos conflitos. ${ }^{5}$

É necessário perceber, então, que a postura atual da jurisdição constitucional brasileira está baseada (de forma ortodoxa ou não) em uma específica compreensão da Constituição. Embora reconheça uma diversidade de concepções, segundo Barroso, existem algumas características comuns a esse novo constitucionalismo: a ênfase na força normativa da Constituição, a expansão da jurisdição constitucional e a reelaboração da interpretação constitucional (especificamente, do papel da norma e do intérprete). ${ }^{6}$

Outro fator de impulsão do ativismo judicial no Brasil, como destacado por Elival da Silva Ramos, é o modelo de Estado intervencionista. ${ }^{7}$ Desde a Constituição de 1934, o modelo de Estado adotado no Brasil é o de um Estado forte, identificado, principalmente, por meio das funções legislativa e administrativa. No entanto, com o tempo, sobre o Judiciário também passaram a recair as expectativas e pressões da sociedade por uma maior efetivação dos fins constitucionais, incluindo a fruição de direitos sociais ou a extensão de benefícios. ${ }^{8}$

Com base nessa concepção o Supremo Tribunal Federal construiu um "procedimento" para a concessão judicial de certos direitos sociais, como a saúde (STA no 175); estendeu direitos civis a novos grupos, como por meio da ampliação da união estável (ADI no 4.277); e, mais recentemente, possibilitou a estruturação de políticas públicas diretamente pelo Judiciário, por meio do reconhecimento do estado de coisas inconstitucional (ADPF no 347).

Como consequência, a interpretação constitucional ganhou lugar de destaque no Supremo Tribunal Federal (o que, mesmo em um sistema romanogermânico, acaba pautando a atuação das instâncias inferiores), ${ }^{9}$ quer explícita, quer implicitamente, e impõe uma reflexão sobre seu fundamento e seus limites. Afinal, como será desenvolvido ao longo do trabalho, é a partir da adoção de determinada concepção sobre a Constituição que será definida a postura do

5 BARROSO, Luís Roberto. O controle de constitucionalidade no direito brasileiro: exposição sistemática da doutrina e análise crítica da jurisprudência. 4. ed. São Paulo: Saraiva, 2009. p. 331 e ss.

6 BARROSO, Luís Roberto. Curso de direito constitucional contemporâneo. 4. ed. São Paulo: Saraiva, 2013. p. 288.

7 RAMOS, Elival da Silva. Ativismo judicial: parâmetros dogmáticos. 2. ed. São Paulo: Saraiva, 2015.

8 RAMOS, Elival da Silva. Ativismo judicial: parâmetros dogmáticos. 2. ed. São Paulo: Saraiva, 2015. p. 285-286.

9 RAMOS, Elival da Silva. Ativismo judicial: parâmetros dogmáticos. 2. ed. São Paulo: Saraiva, 2015. p. 109. 
Judiciário. Consequentemente, conforme a teoria da interpretação constitucional adotada pela prática judicial, as soluções dos casos concretos serão opostas.

Um exemplo emblemático sobre as conclusões antagônicas que podem ser obtidas em decorrência da opção por uma postura ativista ou não ativista pode ser percebido no caso do aborto. Há, atualmente, um debate no Supremo Tribunal Federal sobre a constitucionalidade ou não das normas legais que tipificam a interrupção voluntária da gravidez. Essa discussão foi introduzida, de forma lateral, no Habeas Corpus no 124.306, julgado em novembro de 2016, pela Primeira Turma do Supremo Tribunal. ${ }^{10} \mathrm{Em}$ seguida, em março de 2017, foi ajuizada a Arguição de Descumprimento de Preceito Fundamental no 442, com o objetivo de que seja declarada a incompatibilidade com a Constituição de 1988 dos artigos do Código Penal que criminalizam a prática do aborto.

O ponto central da questão é que houve um debate sobre a proibição ou permissão da interrupção voluntária da gravidez durante a Constituinte de 1987/1988. Alas favoráveis e contrárias se mobilizaram, ambas desejando que a futura Constituição expressamente permitisse ou proibisse o aborto. Ao final, a decisão da Constituinte foi não tomar uma decisão (por mais paradoxal que soe). A decisão foi exatamente a de permitir que o legislador tenha liberdade, conforme o momento histórico, para optar por um dos caminhos. ${ }^{11}$

Como se percebe, o Supremo Tribunal Federal tomar uma postura construtiva ou contida na análise desse caso depende da sua concepção de Constituição e de interpretação constitucional. Depende, especialmente, da relevância atribuída à decisão da Constituinte e à sua autopercepção como competente pelo controle de constitucionalidade. Por isso, a análise do originalismo envolve a análise do ativismo judicial, pelo menos no Brasil.

\section{Sobre uma teoria do ativismo judicial}

De início, devemos observar que o ativismo não é um tipo de teoria, quer sobre a Constituição, o Judiciário ou a interpretação. Talvez por isso no Brasil não estão claras as circunstâncias ou hipóteses em que se dá o ativismo judicial. No entanto, sendo essa postura judicial a consequência de alguma concepção constitucional, é necessário esboçar (ou, pelo menos, tentar) uma teoria sobre o ativismo.

10 BRASIL. Supremo Tribunal Federal. Primeira Turma. HC 124.306. Rel. Min. Marco Aurélio. Rel. p/ Acórdão Min. Roberto Barroso, j. 9.8.2016.

11 ROCHA, Maria Isabel Baltar da. A discussão política sobre aborto no Brasil: uma síntese. Revista Brasileira de Estudos da População, São Paulo, v. 23, n. 2, p. 369-374, dez. 2006. 
Heidi Hurd procurar estruturar uma teoria sobre o ativismo judicial. ${ }^{12}$ Dessa forma, diferencia alguns casos centrais em que os juízes são chamados a ter uma postura ativa e construtiva na solução dos casos. Ou seja, situações em que, buscando concretizar a Constituição, os juízes assumem uma postura de maior e mais intensa participação e interferência na esfera dos demais poderes. ${ }^{13}$ São hipóteses em que o Judiciário assume o papel de protagonista na condução de transformações sociais, segundo Conrado Hübner. ${ }^{14}$

Nessa conceituação de ativismo judicial, ressalva Elival Ramos, deve ser observado que o papel dos juízes é diferente na tradição romano-germânica e na tradição anglo-saxônica. Nesse sentido, o conceito amplo de ativismo judicial decorre de uma concepção anglo-saxônica de direito, em que a atuação dos juízes já é, de certa forma, mais abrangente, dada a importância dos precedentes para a configuração do direito. Nesse caso, o ativismo se manifesta tanto como um exercício regular da função jurisdicional, quanto como uma violação dos limites impostos pelo legislador. ${ }^{15}$ Em uma tradição civilística, dada a primazia da lei, esse ativismo judicial se apresenta como um dilema à teoria da separação dos poderes, dada a distinção mais clara das funções legislativa e judiciária (em comparação com a common law).

$\mathrm{Na}$ busca por identificar o lócus do ativismo judicial, Heidi Hurd destaca alguns casos em que ele se manifesta. Uma primeira forma de ativismo se manifesta quando a literalidade da norma está em conflito com a sua finalidade. Hurd destaca que, nesse caso, cumprir a literalidade da lei causaria um resultado indesejado quando se considera o propósito da lei. ${ }^{16}$ Nesse ponto vale destacar um conceito trazido por Heidi Hurd que é útil não apenas à compreensão do ativismo, mas do próprio originalismo. Hurd compreende a literalidade da norma como o sentido semântico no contexto de seu uso jurídico comum (seja dos legisladores originais ou da audiência atual, conforme o caso). ${ }^{17}$

De acordo com Heidi Hurd, em geral, dificilmente há de se preocupar com algum tipo de ativismo judicial enquanto os intérpretes buscam a intenção original

2 HURD, Heidi M. In defense of judicial activism. Conference on the moral obligations of judges, 2018. No prelo.

13 BARROSO, Luís Roberto. O controle de constitucionalidade no direito brasileiro: exposição sistemática da doutrina e análise crítica da jurisprudência. 4. ed. São Paulo: Saraiva, 2009. p. 335.

14 MENDES, Conrado Hübner. Direitos fundamentais, separação de poderes e deliberação. São Paulo. 219 p. Tese (Doutorado em Ciência Política) - Universidade de São Paulo, São Paulo, 2008. p. 101.

15 RAMOS, Elival da Silva. Ativismo judicial: parâmetros dogmáticos. 2. ed. São Paulo: Saraiva, 2015. p. 112.

16 HURD, Heidi M. In defense of judicial activism. Conference on the moral obligations of judges, 2018. No prelo. p. 3.

17 HURD, Heidi M. In defense of judicial activism. Conference on the moral obligations of judges, 2018. No prelo. p. 3. 
ou o uso comum atual. ${ }^{18}$ Ao contrário, é mais provável que o ativismo judicial seja um ponto relevante quando o intérprete questiona esse significado fixo e considera que ele limita a possibilidade de uma teorização normativa.

No entanto, mesmo em um contexto de significado claro, há espaço para o ativismo judicial. Por isso, a autora até menciona a possibilidade de dúvidas e questionamentos quanto ao significado das normas constitucionais, mas a primeira forma de ativismo por ela destacado pressupõe a existência de um significado claro para a norma, mas que, caso aplicado, causará um resultado injusto, segundo a moralidade da comunidade política. ${ }^{19}$ Não porque seja a finalidade da lei (no sentido de função dentro do ordenamento jurídico e na organização social) ou a intenção do legislador (real ou ideal) o resultado injusto, mas, nas circunstâncias do caso, ele ocorrerá.

A postura a ser assumida pelo magistrado nesse caso é uma postura moral (que não é livre de valores, portanto) de realizar o propósito da lei, mesmo que isso implique o descumprimento de sua literalidade. ${ }^{20}$ Essa hipótese de ativismo pressupõe que a identificação do propósito da lei não é uma atividade neutra e que não deve ser ignorada no processo de interpretação.

O segundo caso de ativismo destacado por Hurd é quando a lei (em sua literalidade e em seu propósito) entra em conflito com as demandas da moralidade política. Nesse caso, há uma norma jurídica com um significado claro e um propósito bem definido, especialmente considerando a finalidade objetiva da lei, e não a possível intenção (subjetiva) do legislador. No entanto, ambos convergem em um resultado moralmente absurdo. ${ }^{21}$

O caminho seria, nesse caso, comparar o valor consubstanciado na literalidade e na finalidade da lei em relação ao demais valores em concorrência (all-things-considered), de forma a identificar se é um valor suficientemente denso a ponto de superar os demais. Esse modelo de adjudicação torna o julgamento um ato carregado de valor. É, portanto, contra esse tipo específico de ativismo judicial contra o qual muitos intérpretes se levantam, como o Justice Scalia. ${ }^{22}$ Nesse caso (e, em certa medida, nos dois anteriores), o ativismo judicial se torna

18 HURD, Heidi M. In defense of judicial activism. Conference on the moral obligations of judges, 2018. No prelo. p. 4.

19 HURD, Heidi M. In defense of judicial activism. Conference on the moral obligations of judges, 2018. No prelo. p. 6.

20 HURD, Heidi M. In defense of judicial activism. Conference on the moral obligations of judges, 2018. No prelo. p. 12.

21 HURD, Heidi M. In defense of judicial activism. Conference on the moral obligations of judges, 2018. No prelo. p. 13.

22 HURD, Heidi M. In defense of judicial activism. Conference on the moral obligations of judges, 2018. No prelo. p. 14. 
uma questão de filosofia política, e um dos principais pontos controvertidos diz respeito à legitimidade dos juízes para essa tarefa. ${ }^{23}$

Quando Dworkin propõe uma concepção de direito e de interpretação judicial baseada em uma consideração valorativa (all-things-considered), caminha para um ativismo deste tipo - embora também possa conduzir a um ativismo na forma apresentada a seguir. ${ }^{24}$ Afinal, o essencial à interpretação nesse modelo é a consideração sobre os valores em jogo, que possibilita a superação da aplicação do resultado "claro" da lei (quando contrário a esses valores) em prol de uma alternativa construída judicialmente (em acordo com os valores considerados de forma integral).

No entanto, além desses casos principais apontados por Hurd, parece que o ativismo judicial brasileiro é muito mais presente em outro caso menos destacado. As concepções apresentadas por Hurd pressupõem um tipo de consenso predominante no uso e na identificação da finalidade da lei - para não mencionar a questão da moralidade política, que é ainda mais complexa. No entanto, pelo menos outra hipótese pode levar a um ativismo judicial exatamente pela falta de um consenso claro sobre o uso e a finalidade das normas. ${ }^{25}$

A Constituição frequentemente utiliza expressões sobre as quais não há um uso definido ou um consenso majoritário. Por exemplo, quando a Constituição inclui uma norma assegurando a liberdade de expressão, há um uso predominante no sentido de proteger as manifestações contra a censura. No entanto, esse uso é de pouca importância prática, uma vez que o conceito e a extensão do que deve ser considerado como censura é algo aberto e dependente de preenchimento por alguma concepção política. Da mesma forma, a extensão da cláusula pétrea que protege a federação brasileira (art. 60, §4ํ, I, CRFB/1988) não possui um uso específico claro que defina sua extensão. 0 mesmo poderia ser dito sobre a saúde, a educação e uma série de outros direitos prevista de forma genérica na Constituição.

O ativismo judicial brasileiro parece ser exatamente uma decorrência desse tipo de cláusula. Dessa forma, o Judiciário assume a postura de tentar definir esses conceitos genéricos, independentemente da manifestação dos demais poderes ou mesmo contrariamente à opção por eles apresentada. Esses parecem ser os principais casos de ativismo judicial no Supremo Tribunal Federal - mas a confirmação exige uma pesquisa empírica posterior.

23 RAMOS, Elival da Silva. Ativismo judicial: parâmetros dogmáticos. 2. ed. São Paulo: Saraiva, 2015. p. 113.

24 DWORKIN, Ronald. Law's empire. Cambridge: Harvard University Press, 1986. p. 45 e ss.

25 HURD, Heidi M. In defense of judicial activism. Conference on the moral obligations of judges, 2018. No prelo. p. 5. 


\section{Constitucionalismo, originalismo e interpretação judicial}

Primeiramente, é importante destacar que as teorias sobre a interpretação constitucional não são facilmente separáveis das teorias que dizem respeito à própria natureza, objetivo e autoridade das constituições. Por isso, as concepções originalistas e as não originalistas estão assentadas em teorias constitucionais distintas. Isso, contudo, não impede seu cotejamento, pois ambas ponderam alguns elementos em comum - embora atribuindo importância distinta a cada um deles: significado, intenção, precedente e teoria. ${ }^{26}$ Essa ponderação será determinante para a atuação judicial e para a determinação da extensão da interpretação constitucional.

O constitucionalismo é uma ideia ou movimento associado à fundação dos Estados Unidos de que o governo deve ser limitado pelo direito e de que sua legitimidade e autoridade depende da observância desses limites. Ademais, esses limites devem estar consagrados em regras escritas - as quais devem ser preservadas. No entanto, isso cria um problema crucial em regimes democráticos, sobre quem, como e dentro de quais limites deve ser interpretada a Constituição. Ou seja, um problema de interpretação constitucional. ${ }^{27}$

Essa discussão pode ser abordada a partir de diversas perspectivas distintas, mas uma merece destaque, a que distingue originalismo e não originalismo. Para o originalismo, a Constituição está preocupada em limitar o arbítrio do governo, inclusive do poder judicial, por isso a atuação do Judiciário deve ser mais deferente às decisões do Legislativo e do povo que representa. Por outro lado, concepções não originalistas (como as que sustentam o ativismo judicial do Supremo Tribunal Federal) identificam a finalidade da Constituição com a proteção das minorias e, portanto, estão abertas a interpretações mais construtivas que protejam esses grupos. ${ }^{28}$ Por isso, para o originalismo a interpretação judicial das normas constitucionais encontra-se vinculada ao entendimento dos que escreveram a ratificaram a Constituição, enquanto para os não originalistas o entendimento vigente na promulgação da Constituição não é vinculante para os juízes atuais. ${ }^{29}$

A análise dessas duas posições pode ser diferenciada em dois planos, o epistemológico e o político. No plano epistemológico, a preocupação é sobre a

26 WALUCHOW, Wilfrid J. A common law theory of judicial review. the living tree. Cambridge: Cambridge University Press, 2007. p. 53.

27 WALUCHOW, Wilfrid J. Constitutionalism. In: ZALTA, Edward N. (Ed.). The Stanford Encyclopedia of Philosophy, Spring 2018. Disponível em: https://plato.stanford.edu/archives/spr2018/entries/ constitutionalism/. Acesso em: 16 fev. 2019.

28 WALUCHOW, Wilfrid J. A common law theory of judicial review. the living tree. Cambridge: Cambridge University Press, 2007. p. 52-53.

29 MORALES, Cesar Mecchi. Originalismo e interpretação constitucional. 274 f. Tese (Doutorado em Direito) - Faculdade de Direito da Universidade de São Paulo, São Paulo, 2011. 
possibilidade da identificação de um sentido original da Constituição (seja no texto, seja na intenção dos Constituintes). No plano político, a discussão é sobre o papel da Constituição em Estados Democráticos e a autoridade com a palavra final sobre seu conteúdo.

Nesse sentido, a discussão se aproxima daquela elaborada por Mendes sobre a revisão judicial (judicial review). ${ }^{30}$ Segundo Conrado Hübner, a discussão sobre o controle de constitucionalidade envolve uma dimensão substancial, sobre a necessidade de contenção do poder político, e uma dimensão institucional, sobre como e quem deve realizá-la. ${ }^{31}$ Essa dimensão institucional diz respeito ao problema político entre originalismo e não originalismo, sobre quem deve ter a palavra final na interpretação constitucional. No entanto, são dimensões interligadas, pois a restrição à interpretação judicial depende da possibilidade de identificação de um significado fixo. ${ }^{32}$

Para o originalismo, seria possível identificar critérios mais ou menos fixos, embora com distintos métodos para identificar essa fixação, para definir o significado das normas constitucionais - princípio da fixação - e esse significado limita a atuação judicial - princípio da restrição. ${ }^{33}$

Dessa forma, o originalismo é uma teoria que, em tese, exige uma maior limitação da interpretação constitucional (em sua dimensão política), vinculando o intérprete a elementos relativamente objetivos (sua dimensão epistemológica). Nesse sentido, é importante destacar que o originalismo pode ser apresentado com, pelo menos, duas formas principais: uma versão intencionalista, baseada na vontade do legislador original, e uma versão textualista, baseada no significado das expressões. ${ }^{34}$

A versão intencionalista pressupõe um tipo de diálogo entre o Constituinte e o magistrado, no qual a correta compreensão da manifestação do emissor pressupõe a identificação da intenção manifesta. Por sua vez, textualismo pressupõe que o significado do texto poderia ser identificado a partir do uso jurídico ordinário dos termos. ${ }^{35}$ Segundo Waluchow, o originalismo tem ganhado mais força a partir dessa segunda perspectiva, de um significado público comum. ${ }^{36}$

MENDES, Conrado Hübner. Controle de constitucionalidade e democracia. Rio de Janeiro: Elsevier, 2008. MENDES, Conrado Hübner. Controle de constitucionalidade e democracia. Rio de Janeiro: Elsevier, 2008. p. 144.

32 SOLUM, Lawrence B. Originalism and constitutional construction. Fordham Law Review, New York, v. 82, p. 453-537, 2013.

33 SOLUM, Lawrence B. Originalism and constitutional construction. Fordham Law Review, New York, v. 82, p. 453-537, 2013. p. 459-460.

34 DWORKIN, Ronald. Justice in robes. Cambridge: Harvard University Press, 2006. p. 118.

35 HURD, Heidi M. In defense of judicial activism. Conference on the moral obligations of judges, 2018. No prelo.

36 WALUCHOW, Wilfrid J. Constitutionalism. In: ZALTA, Edward N. (Ed.). The Stanford Encyclopedia of Philosophy, Spring 2018. Disponivel em: https://plato.stanford.edu/archives/spr2018/entries/ constitutionalism/. Acesso em: 16 fev. 2019. 
Sobre o textualismo, Akhil Amar destaca que embora muitos textualistas busquem conceituar e interpretar o sentido de um termo ou expressão de forma isolada (o que acaba por tornar demasiadamente frágil o textualismo), é necessário que essa interpretação textual se dê por meio da comparação e do contraste de uma expressão específica com outros usos ao longo do texto da Constituição. ${ }^{37}$ Akhil Amar denominou essa técnica de "intratextualismo". Dessa forma, não seria necessário buscar uma intenção original, pois a leitura da Constituição como um documento integral (e não um amontoado de cláusulas) daria a definição de seus próprios conceitos (independentemente de se intencionado pelos constituintes). ${ }^{38}$

A principal impugnação epistemológica do não originalismo reside na possibilidade de identificação desse significado fixo. Por um lado, pois não existem critérios claros para identificar nos trabalhos legislativos (ou em algum elemento objetivo) a intenção dos legisladores. Além disso, o transcurso do tempo implica alterações significativas na sociedade, criando situações novas e não previstas inicialmente e dificultando o acesso à possível intenção original presente na Constituinte. ${ }^{39}$

Por outro lado, se é verdade que existem textos normativos com baixo conteúdo moral (e, portanto, de definição mais precisa e consensual), as normas constitucionais possuem alta carga valorativa (com diversos princípios abstratos), sendo de interpretação frequentemente controversa. Sem o elemento de fixação do significado, o elemento de restrição judicial ficaria prejudicado. Portanto, concluem os não originalistas, o significado das normas constitucionais é dinâmico e vivo, e não estático e fixo..$^{40}$

Não obstante, deve-se observar que a ausência da identificação exata do significado de uma expressão constitucional nem sempre será um obstáculo intransponível para o originalismo. Uma visão originalista coerente irá, ao reconhecer essa limitação, deferir ao Legislativo a autoridade para solucionar a questão.

Da mesma forma, salvo alguma versão ingênua, o originalismo não pressupõe que o significado de uma expressão não sofra alteração com o tempo. No entanto, para o Judiciário existe um marco temporal vinculante, o qual não impede a alteração de significado pelo Legislativo. 0 que seria incoerente e ilegítimo - no marco do originalismo - seria o Judiciário impedir que o Legislativo alterasse o

37 AMAR, Akhil Reed. Intratextualism. Harvard Law Review, Cambridge, v. 112, n. 4, p. 747-827, 1999.

38 AMAR, Akhil Reed. Intratextualism. Harvard Law Review, Cambridge, v. 112, n. 4, p. 747-827, 1999. p. 789-790.

39 WALUCHOW, Wilfrid J. Constitutionalism. In: ZALTA, Edward N. (Ed.). The Stanford Encyclopedia of Philosophy, Spring 2018. Disponível em: https://plato.stanford.edu/archives/spr2018/entries/ constitutionalism/. Acesso em: 16 fev. 2019.

40 WALUCHOW, Wilfrid J. A common law theory of judicial review: the living tree. Cambridge: Cambridge University Press, 2007. 
significado dos conceitos em razão de um significado anterior. Desta forma, a questão permanece sobre quem deve conduzir essa alteração conceitual.

Com tudo isso, não devemos concluir que o originalismo, de forma geral, pressupõe que a interpretação seja uma tarefa simples, neutra ou automática. Talvez alguma versão textualista ingênua conclua dessa forma, mas não é uma defesa geral do originalismo. É possível e provável que haja um conteúdo moral na Constituição, mas a seleção e definição dele foi dado pelo Constituinte - e não por uma ideia atualizada de moralidade da comunidade política que seria definida pelos juízes. Logo, havendo a necessidade do preenchimento moral de certos conceitos constitucionais, isso deve ser por meio dessa opção expressa anteriormente.

A preocupação com as decisões anteriores pode ser relacionada ao ideal de proteção das expectativas. Embora ele esteja associado ao convencionalismo, também é útil à compreensão da defesa do originalismo. ${ }^{41}$ Seja em sua forma intencionalista ou na modalidade textualista, o originalismo pressupõe um grau razoável de objetividade na interpretação constitucional, o que seria adequado a proteger aqueles que atuam com base nos princípios formadores da Constituição ou em seu texto expresso. 0 originalismo (nas duas formas) habilitaria as pessoas a anteverem as consequências jurídicas de suas ações, ${ }^{42}$ considerando, obviamente, uma concepção em que a finalidade do direito é orientar o comportamento das pessoas. 43

Por fim, um ponto que deve ser mencionado aqui - embora sem grande oportunidade para desenvolvimento no presente trabalho - é a discussão sobre a legitimidade da Constituição. Isto é, sobre a legitimidade para um documento elaborado em determinado momento histórico vincular as gerações futuras. A pergunta seria: por quanto tempo dura a legitimidade de uma Constituição? ${ }^{44}$

Esta é uma crítica normalmente voltada ao originalismo, na sua tentativa de voltar às origens constitucionais ou de encontrar um significado fixo no tempo. A concepção originalista sofreria esse déficit de legitimidade entre as gerações ao vincular a interpretação judicial de forma excessiva à "mão morta do passado" (dead hand of the past), incapazes de responder às circunstâncias de mudança. ${ }^{45}$

1 DWORKIN, Ronald. Law's empire. Cambridge: Harvard University Press, 1986.

42 HURD, Heidi M. In defense of judicial activism. Conference on the moral obligations of judges, 2018. No prelo. p. 5.

43 WALUCHOW, Wilfrid J. Constitutionalism. In: ZALTA, Edward N. (Ed.). The Stanford Encyclopedia of Philosophy, Spring 2018. Disponivel em: https://plato.stanford.edu/archives/spr2018/entries/ constitutionalism/. Acesso em: 16 fev. 2019.

44 MENDES, Conrado Hübner. Controle de constitucionalidade e democracia. Rio de Janeiro: Elsevier, 2008. p. 144.

45 WALUCHOW, Wilfrid J. Constitutionalism. In: ZALTA, Edward N. (Ed.). The Stanford Encyclopedia of Philosophy, Spring 2018. Disponível em: https://plato.stanford.edu/archives/spr2018/entries/ constitutionalism/. Acesso em: 16 fev. 2019. 
Contudo, se a legitimidade do Judiciário reside nos poderes que este documento lhe confere e na busca por suas finalidades, por meio de uma interpretação construtiva, ${ }^{46}$ parece que o problema alcança também o não originalismo, embora de outra forma. A construção judicial da interpretação constitucional é feita com base em uma legitimidade dada por uma carta não elaborada pela presente geração e em normas que podem ser substancialmente alteradas pelo Judiciário independentemente da (e até contrariamente à) opinião do Legislativo - em tese representantes da geração atual. Se assim o for, parece que a legitimidade do Judiciário nesse contexto é autopoiética, uma vez que vem de um documento que está sendo construído interpretativamente por ele mesmo.

A seu turno, o originalismo pressupõe que a opção realizada originalmente deve permanecer vinculando as gerações futuras até que venha uma nova decisão dos representantes atuais. Nesse caso, é dever de uma corte originalista ser deferente ao legislador. Embora o problema persista, parece que alcança as duas concepções, embora, ao menos aparentemente, o originalismo guarde maior coerência. Obviamente o problema epistemológico persiste, mas este é um ponto da dimensão política das teorias. ${ }^{47}$

Considerando o esboço teórico apresentado sobre o ativismo judicial e o originalismo, é possível tentarmos religá-los dentro da prática jurídica brasileira - sem perder de vista os desafios e os limites da recepção de uma teoria constitucional desenvolvida em outro contexto político, social e filosófico.

\section{Originalismo no Brasil: possibilidades e desafios}

De início, é importante observar que o ativismo judicial desenvolvido no Brasil pode ser identificado como resultado da adoção de uma teoria da interpretação constitucional não originalista. Como destacado, o ativismo judicial está relacionado a uma postura de maior e mais intensa participação do Judiciário na busca da concretização dos fins constitucionais, com maior interferência no espaço de atuação dos demais poderes. ${ }^{48}$ Dessa forma, é uma postura baseada em determinada teoria da interpretação constitucional. Afinal, é necessário que o Judiciário identifique essas finalidades constitucionais e busque os meios

46 BARROSO, Luís Roberto. O controle de constitucionalidade no direito brasileiro: exposição sistemática da doutrina e análise crítica da jurisprudência. 4. ed. São Paulo: Saraiva, 2009.

47 Esse problema exige uma pesquisa à parte, especialmente baseada em uma discussão sobre filosofia da linguagem e teoria da Constituição.

48 BARROSO, Luís Roberto. O controle de constitucionalidade no direito brasileiro: exposição sistemática da doutrina e análise crítica da jurisprudência. 4. ed. São Paulo: Saraiva, 2009. p. 335. 
necessários à sua concretização, em uma visão muito mais viva do que estática para usar os termos de Waluchow. ${ }^{49}$

Considerando o posicionamento de Dworkin de que a teoria do direito deve guardar relação com a prática jurídica, ${ }^{50}$ uma teoria constitucional adequada deve ser adequada à prática jurídica brasileira. Nesse sentido, o maior grau de objetividade presente no originalismo parece ser útil ao Judiciário de novas democracias, como o Brasil. Essa afirmação, no entanto, exige uma discussão mais ampla sobre a teoria da organização dos poderes. A hipótese aqui levantada, por outro lado, é que em novas democracias o Judiciário deve atuar como um elemento de estabilização institucional por meio de uma interpretação constitucional razoavelmente constante.

É verdade que em países como os Estados Unidos e a Alemanha do PósGuerra (mesmo sendo uma nova democracia) uma maior intervenção do Judiciário na esfera política não causou instabilidade ou prejuízo aos tribunais, ${ }^{51}$ mas este não parece ser o caso do Brasil (e das democracias latino-americanas). Parece ser mais coerente no sistema constitucional nacional a concepção baseada na tese da estabilidade. ${ }^{52}$

A análise desse ponto pressupõe a discussão sobre o papel de uma Suprema Corte, especialmente se ela deve ter uma postura construtiva (e ativa) nos embates políticos, auxiliando a construção de direitos e da própria democracia, ou se deve ter uma função de estabilização, contrabalanceando a atuação do Executivo e do Legislativo.

A tese de Epstein é a de que os tribunais, em conjunto com legisladores e governantes, têm um papel na afirmação (establishment) e manutenção de democracias constitucionais. ${ }^{53}$ Nada surpreendente nesse ponto inicial. 0 interessante da tese, no entanto, é a afirmação de que a função dos tribunais nesse “jogo democrático" é a de estabilização política.

Essa tese parece ser adequada ao contexto brasileiro, pois foi feita a partir do contexto russo e do Leste europeu, ${ }^{54}$ em que os embates políticos entre os

49 WALUCHOW, Wilfrid J. A common law theory of judicial review. the living tree. Cambridge: Cambridge University Press, 2007.

50 DWORKIN, Ronald. Law's empire. Cambridge: Harvard University Press, 1986.

51 MENDES, Conrado Hübner. Controle de constitucionalidade e democracia. Rio de Janeiro: Elsevier, 2008. p. 139.

52 EPSTEIN, Lee; KNIGHT, Jack; SHVETSOVA, Olga. The Role of Constitutional Courts in the Establishment and Maintenance of Democratic Systems of Government. Law \& Society Review, v. 35, n. 1, pp. 117-164, 2001.

53 EPSTEIN, Lee; KNIGHT, Jack; SHVETSOVA, Olga. The role of constitutional courts in the establishment and maintenance of democratic systems of government. Law \& Society Review, Amherst (Massachusetts), v. 35, n. 1, p. 117-164, 2001. p. 117.

54 EPSTEIN, Lee; KNIGHT, Jack; SHVETSOVA, Olga. The role of constitutional courts in the establishment and maintenance of democratic systems of government. Law \& Society Review, Amherst (Massachusetts), v. 35 , n. 1 , p. $117-164,2001$. p. 117. 
poderes e os desafios à preservação do constitucionalismo democrático são próximos à atualidade brasileira.

Os autores reconhecem, de início, que a comunidade jurídica e política tem recebido o papel ativo dos tribunais como uma busca por garantir a supremacia da Constituição e um esforço de democratização dos países (após o final da II Guerra). ${ }^{55}$ No entanto, essa análise não pode tratar os tribunais como entidades fora (ou acima) dos processos políticos. ${ }^{56}$

Essa tese explica porque a ação dos tribunais em países com democracias em consolidação (especificamente a Rússia e o Leste europeu) é tão distinta da ação dos tribunais em democracias consolidadas (como Europa Ocidental e Estados Unidos). Em tais contextos, os tribunais tendem a ser mais tolerantes (por certo período de tempo) com as autoridades políticas. A necessidade dessa postura, destacam os autores, decorre da complexidade do processo de consolidação democrática. ${ }^{57}$

Embora a promulgação da Constituição seja um marco importante para a afirmação de um regime democrático, sua consolidação depende de um ajuste na estrutura institucional e na relação entre os atores políticos (incluindo os tribunais). Nesses contextos, o principal papel dos tribunais será atuar com base no sistema constitucional sobre o qual já há um acordo substancial, afastandose, pelo menos temporariamente, das questões sobre as quais há um grande desacordo. ${ }^{58}$

Se for adotada a perspectiva de que o papel dos tribunais (e do Supremo Tribunal Federal, em especial) é o de ser uma instituição de estabilização constitucional, quando a Suprema Corte passa a ser parte integrante de sucessivos embates políticos, isso afeta a própria percepção sobre a autoridade da Constituição e lança descrédito na efetividade institucional do Tribunal. ${ }^{59}$

55 EPSTEIN, Lee; KNIGHT, Jack; SHVETSOVA, Olga. The role of constitutional courts in the establishment and maintenance of democratic systems of government. Law \& Society Review, Amherst (Massachusetts), v. 35, n. 1, p. 117-164, 2001. p. 118.

56 EPSTEIN, Lee; KNIGHT, Jack; SHVETSOVA, Olga. The role of constitutional courts in the establishment and maintenance of democratic systems of government. Law \& Society Review, Amherst (Massachusetts), v. 35, n. 1, p. 117-164, 2001. p. 120.

57 EPSTEIN, Lee; KNIGHT, Jack; SHVETSOVA, Olga. The role of constitutional courts in the establishment and maintenance of democratic systems of government. Law \& Society Review, Amherst (Massachusetts), v. 35, n. 1, p. 117-164, 2001. p. 155.

58 EPSTEIN, Lee; KNIGHT, Jack; SHVETSOVA, Olga. The role of constitutional courts in the establishment and maintenance of democratic systems of government. Law \& Society Review, Amherst (Massachusetts), v. 35, n. 1, p. 117-164, 2001. p. 156.

59 EPSTEIN, Lee; KNIGHT, Jack; SHVETSOVA, Olga. The role of constitutional courts in the establishment and maintenance of democratic systems of government. Law \& Society Review, Amherst (Massachusetts), v. 35 , n. 1 , p. $117-164,2001$. p. 128. 
Nesse sentido, enquanto os demais poderes tendem a estar mais sujeitos às influências do momento, o Judiciário tenderia, por meio de uma adstrição ao texto ou à vontade do constituinte originário, a conter as mudanças abruptas. Essa função de estabilização dentro na Constituição de 1988 poderia ser percebida nas denominadas “cláusulas pétreas", que tentam limitar mudanças abruptas na vontade política identificável no Texto Constitucional em razão de circunstâncias políticas transitórias. ${ }^{60}$

Sobre isso, um dos argumentos dos adeptos de uma concepção de "Constituição viva" a fim de fundamentar um ativismo judicial baseia-se nos problemas no campo do Legislativo, como a crise de legitimidade e a dificuldade de oferecer respostas às demandas sociais em um prazo razoável. ${ }^{61}$ No entanto, a maior presença do Judiciário no espaço de decisões políticas - por meio de decisões judiciais - tem lançado as instâncias judiciais, especialmente o Supremo Tribunal Federal, para o centro da crise. Em muitas democracias o embate é favorável à Suprema Corte, como nos Estados Unidos e mesmo na Alemanha do Pós-Guerra. No entanto, historicamente quando isso ocorreu no Brasil o desfecho foi prejudicial ao Tribunal, como aponta Mendes. ${ }^{62}$ Esse talvez seja o motivo de preocupação crescente com o ativismo judicial nacional.

Nesse sentido, é interessante observar que algumas (não necessariamente todas) defesas da contenção da jurisdição constitucional pressupõem alguma base originalista. Conrado Hübner Mendes, por exemplo, defende uma limitação à revisão judicial de uma emenda constitucional que tenha por objetivo alterar uma interpretação dada pelo Supremo Tribunal Federal. ${ }^{63}$ Nesse caso, segundo Mendes, quando o Supremo Tribunal Federal

declara a inconstitucionalidade de emenda constitucional, sufoca os meios de ação dos canais representativos. Mesmo que o Tribunal fosse capaz de aferir erros e acertos do legislador, o regime democrático deve possibilitar que dada comunidade aprenda com os próprios erros. ${ }^{64}$

60 SILVA, Luís Virgílio Afonso da. Ulisses, as sereias e o poder constituinte derivado. Revista de Direito Administrativo, Rio de Janeiro, v. 226, p. 11-32, out. 2001.

61 BARROSO, Luís Roberto. O controle de constitucionalidade no direito brasileiro: exposição sistemática da doutrina e análise crítica da jurisprudência. 4. ed. São Paulo: Saraiva, 2009. p. 331 e ss.

62 MENDES, Conrado Hübner. Controle de constitucionalidade e democracia. Rio de Janeiro: Elsevier, 2008. p. 139.

63 MENDES, Conrado Hübner. Controle de constitucionalidade e democracia. Rio de Janeiro: Elsevier, 2008.

64 MENDES, Conrado Hübner. Controle de constitucionalidade e democracia. Rio de Janeiro: Elsevier, 2008. p. 135. 
Essa tese, se inserida no debate sobre o originalismo, pressupõe que o Legislativo comunica algo ao Judiciário ao aprovar uma alteração constitucional em oposição a uma interpretação judicial dada pelo Tribunal, e que, consequentemente, deve o Judiciário limitar-se por essa decisão legislativa. Isso, mesmo quando a emenda constitucional possui - como é normalmente o caso - relativo grau de abstração, o qual mantém a necessidade de concretização por meio da interpretação judicial. ${ }^{65}$

No entanto, existem algumas dificuldades adicionais no caso brasileiro. Um pressuposto do originalismo interpretativo, especialmente na versão intencionalista, parece ser o compartilhamento de uma concepção política pelos fundadores da Constituição - uma consistência entre os constituintes. ${ }^{66}$

No caso, a versão americana supostamente pressuporia o compartilhamento de uma visão liberal sobre os direitos fundamentais e a organização do Estado, por exemplo. Na verdade, hoje é questionável se realmente há uma concepção política única na base da Constituição americana. No entanto, se efetivamente houver, há uma dificuldade prática na identificação dessa concepção. Dworkin ${ }^{67}$ e Shapiro, ${ }^{68}$ por exemplo, divergem profundamente sobre qual concepção política deve ser aceita, se liberal ou republicana.

Se na Constituição dos Estados Unidos há uma dúvida razoável, na Constituição brasileira de 1988 é concreta a dificuldade de identificação dessa concepção política uníssona de fundo. Ao contrário, o processo de redemocratização e de constitucionalização foi marcado por uma convergência de concepções políticas distintas. Isso fica visível na denominada "Constituição Econômica", que tenta harmonizar movimentos com uma tendência liberal e movimentos intervencionistas. ${ }^{69} \mathrm{~A}$ mesma ausência de consistência pode ser identificada na busca da determinação das expressões usadas pelo constituinte, prejudicando a opção pelo textualismo. ${ }^{70}$

Esse problema pode ser relativamente superado por meio da adoção do significado jurídico comum das expressões, quando houver um consenso razoavelmente estabelecido acerca delas, e por meio da deferência ao Legislativo, para casos controversos e que exigem intensa deliberação moral. Embora talvez nem todos os casos possam ser solucionados por esses meios, tais

\footnotetext{
65 MENDES, Conrado Hübner. Controle de constitucionalidade e democracia. Rio de Janeiro: Elsevier, 2008. p. 135 e ss.

66 WALUCHOW, Wilfrid J. A common law theory of judicial review: the living tree. Cambridge: Cambridge University Press, 2007. p. 54.

67 DWORKIN, Ronald. Justice in robes. Cambridge: Harvard University Press, 2006.

68 SHAPIRO, Scott J. Legality. Cambridge: The Belknap Press of Harvard University Press, 2011.

69 FIGUEIREDO, Leonardo Vizeu. Lições de direito econômico. Rio de Janeiro: Forense, 2010. p. 59 e ss.

70 DWORKIN, Ronald. Justice in robes. Cambridge: Harvard University Press, 2006. p. 120.
} 
caminhos implicariam uma alteração da postura do Supremo Tribunal Federal. Consequentemente, uma relação mais ajustada a uma separação de poderes no contexto de um constitucionalismo democrático em construção.

\section{Conclusão}

Como se pode perceber, a discussão sobre ativismo judicial e interpretação constitucional no Brasil exige um grande esforço teórico, o qual foi apenas iniciado no presente trabalho. Há, em primeiro lugar, uma necessidade de ordenar teoricamente as posições judiciais assumidas pelo Supremo Tribunal Federal, para identificarmos a concepção de Constituição adotada predominantemente pala jurisdição constitucional nacional. Somente depois é possível construir uma teoria da interpretação constitucional adequada à complexidade da realidade brasileira. A partir de então será possível fundamentar a via não originalista atual ou sustentar, de forma mais concreta, sua superação. Em todo caso, o presente trabalho lança alguns argumentos iniciais para a opção por uma via originalista.

O principal desafio ao objetivo do presente trabalho é a ausência de uma discussão sobre o conceito de ativismo judicial no debate de Waluchow sobre o originalismo. Mesmo assim, como se argumentou, a divisão entre originalismo e não originalismo é válida e útil para a compreensão da postura ativista do Supremo Tribunal Federal; especialmente considerando que a Corte defende seu papel como intérprete de uma "Constituição viva”, ou seja, de uma construção jurídica em prol das finalidades constitucionais, rejeitando, por outro lado, concepções assentadas em significados fixos do Texto Constitucional.

Em que pese os desafios apontados, especialmente o epistemológico (não abordado extensivamente na presente pesquisa), a tese deste trabalho é que o originalismo pode contribuir para um ambiente de estabilidade institucional e de maior legitimidade democrática dos poderes, especialmente por meio de uma maior deferência à representação popular presente no Legislativo. Aliás, como se sustentou, talvez a melhor forma de o Judiciário não incidir em uma falta de legitimidade perante a geração presente é limitando-se ao significado fixado anteriormente no Texto Constitucional ou conceder a decisão aos mandatários atuais.

É verdade que, em um país com tradição autoritária e com um Legislativo em constante crise (inclusive de representatividade), parece preocupante uma concepção teórica que limite a ação do Judiciário e destaque o papel dos parlamentares. No entanto, esse é um desafio que precisa ser apresentado e apreciado, quer para ajuste do sistema atual, que é necessário, quer para direcionamento em outro sentido, como se defendeu. 
Espera-se que a presente pesquisa contribua para o debate sobre a possibilidade (ou não) do originalismo no constitucionalismo brasileiro, devendo ser os aspectos teóricos aqui colocados cotejados com a prática jurídica (e judiciária) nacional, especialmente por meio de uma posterior análise da argumentação jurisprudencial.

\title{
An analysis on originalism in the context of the Brazilian judicial activism
}

\begin{abstract}
Brazil has a relatively consolidated system of judicial review, as evidence of this is a prominent place given to the Supreme Court in hard cases. Therefore, it has become a commonplace to assert that the Court adopts an activist position in the exercise of constitutional jurisdiction. However, it is not possible to clearly identify a theory that validates and justifies this mode of action. On the other hand, the theories that contradict this form of manifestation of judicial review are ignored in the national constitutional debate. In this sense, a major Anglo-Saxon debate is between originalism and non-originalism (living constitutionalism) in constitutional interpretation. Therefore, the objective of this work is to receive, in Brazil, this debate already existing in North America, to analyze the interpretive originalism in the context of the judicial activism in the Supreme Court, presenting a critical analysis of both. For this, the paper makes an analysis of the Brazilian constitutional context; presents a framework for understanding the types of judicial activism; discusses the differences between originalism and nonoriginalism; and, finally, analyzes the possibility of insertion of originalism in the Brazilian constitutional system. The research was developed from a bibliographical research, taking as main authors on the Brazilian context Conrado Hübner and Luis Roberto Barroso and, on the originalism, Wilfrid Waluchow and Lawrence Solum.
\end{abstract}

Keywords: Constitutional Interpretation. Supreme Court of Brazil. Originalism. Judicial activism. Judicial review.

Contents: $\mathbf{1}$ Introduction - $\mathbf{2}$ The Brazilian context: constitutionalism and judicial activism - $\mathbf{3}$ On a theory of judicial activism $\mathbf{-} \mathbf{4}$ Constitutionalism, originalism and judicial interpretation $\mathbf{- 5}$ Originalism in Brazil: possibilities and challenges - $\mathbf{6}$ Conclusion - References

\section{Referências}

AMAR, Akhil Reed. Intratextualism. Harvard Law Review, Cambridge, v. 112, n. 4, p. 747-827, 1999.

BARROSO, Luís Roberto. Curso de direito constitucional contemporâneo. 4. ed. São Paulo: Saraiva, 2013.

BARROSO, Luís Roberto. O controle de constitucionalidade no direito brasileiro: exposição sistemática da doutrina e análise crítica da jurisprudência. 4. ed. São Paulo: Saraiva, 2009.

BRASIL. Supremo Tribunal Federal. Primeira Turma. HC 124.306. Rel. Min. Marco Aurélio. Rel. p/ Acórdão Min. Roberto Barroso, j. 9.8.2016.

DWORKIN, Ronald. Justice in robes. Cambridge: Harvard University Press, 2006.

DWORKIN, Ronald. Law's empire. Cambridge: Harvard University Press, 1986.

EPSTEIN, Lee; KNIGHT, Jack; SHVETSOVA, Olga. The role of constitutional courts in the establishment and maintenance of democratic systems of government. Law \& Society Review, Amherst (Massachusetts), v. 35 , n. 1, p. 117-164, 2001. 
FIGUEIREDO, Leonardo Vizeu. Lições de direito econômico. Rio de Janeiro: Forense, 2010.

HURD, Heidi M. In defense of judicial activism. Conference on the moral obligations of judges, 2018. No prelo.

MENDES, Conrado Hübner. Controle de constitucionalidade e democracia. Rio de Janeiro: Elsevier, 2008.

MENDES, Conrado Hübner. Direitos fundamentais, separação de poderes e deliberação. São Paulo. 219 p. Tese (Doutorado em Ciência Política) - Universidade de São Paulo, São Paulo, 2008.

MORALES, Cesar Mecchi. Originalismo e interpretação constitucional. 274 f. Tese (Doutorado em Direito) - Faculdade de Direito da Universidade de São Paulo, São Paulo, 2011.

RAMOS, Elival da Silva. Ativismo judicial: parâmetros dogmáticos. 2. ed. São Paulo: Saraiva, 2015.

ROCHA, Maria Isabel Baltar da. A discussão política sobre aborto no Brasil: uma síntese. Revista Brasileira de Estudos da População, São Paulo, v. 23, n. 2, p. 369-374, dez. 2006.

SHAPIRO, Scott J. Legality. Cambridge: The Belknap Press of Harvard University Press, 2011.

SILVA, Luís Virgílio Afonso da. Ulisses, as sereias e o poder constituinte derivado. Revista de Direito Administrativo, Rio de Janeiro, v. 226, p. 11-32, out. 2001.

SOLUM, Lawrence B. Originalism and constitutional construction. Fordham Law Review, New York, v. 82, p. 453-537, 2013.

WALUCHOW, Wilfrid J. A common law theory of judicial review: the living tree. Cambridge: Cambridge University Press, 2007.

WALUCHOW, Wilfrid J. Constitutionalism. In: ZALTA, Edward N. (Ed.). The Stanford Encyclopedia of Philosophy, Spring 2018. Disponivel em: https://plato.stanford.edu/archives/spr2018/entries/ constitutionalism/. Acesso em: 16 fev. 2019.

Informação bibliográfica deste texto, conforme a NBR 6023:2018 da Associação Brasileira de Normas Técnicas (ABNT):

SOUZA, Elden Borges; PINHEIRO, Victor Sales. Uma análise sobre o originalismo no contexto do ativismo judicial brasileiro. Direitos Fundamentais \& Justiça, Belo Horizonte, ano 14, n. 42, p. 535-554, jan./jun. 2020.

Recebido em: 18.04.2019

Pareceres: 02.05.2019, 17.12.2019

Aprovado em: 19.12.2019 